\title{
Reversal of Disease Phenotype
}

National Cancer Institute

\section{Source}

National Cancer Institute. Reversal of Disease Phenotype. NCI Thesaurus. Code C125205.

Lack of the prior infectious complications or malignancy that preceded a transplant 